\title{
Building Knowing Readers: Unlocking Pleasure
}

\author{
Susan La Marca \\ Youth Literature \& Library Consultant \\ Teacher-Librarian \\ Ivanhoe Girls' Grammar School \\ Australia
}

\begin{abstract}
There is clear evidence of a relationship between pleasure reading and literacy development. Further analysis stresses the centrality of engagement to pleasure. In exploring these relationships the importance of choice, talk, and variety will be discussed. The role the teacher-librarian plays in facilitating interactions with text that promote pleasure and the importance of relationships, knowledge and collection building will be addressed with reference to research and practice. This paper builds on earlier presentations on this and related topics.
\end{abstract}

Reading, Pleasure, Engagement

\section{Introduction}

The creation of a reading culture is important to many school communities and, in particular, to many teacher-librarians. Those who see value in the experience of reading see the creation of this culture, the creation of a community that reads for pleasure, as an integral part of any school's endeavours. In addition to the personal satisfaction obtained from reading, Saxby reminds us that reading has a cultural function claiming; 'we humans live by our own stories, but the stories we hear and read, especially in childhood, help shape our lives and outlook. They provide us with much of our culture' (Saxby, 1997, p. vii). As well as recognising the benefits to literacy development, teachers and teacher-librarians who take pleasure in reading themselves also recognise the role reading can play in students' everyday lives. Reading is both an important skill that enables us to function effectively in society and an experience that increases our understanding of the world around us. Reading can open windows for us into other experiences both real and imagined.

At times, though, the educational sphere becomes fixated with reading as a skill. The idea that reading has intrinsic benefits that, though difficult to assess or determine, cannot be discounted, is a view that does not always hold sway in the realm of educational debate. The pleasures that reading brings and the understandings it can conjure are often not noted. Certainly, in Australia, in today's educational debate, 'scores on the board' often rule decision-making. It is those activities that have a measurable impact on student achievement that garner more funding, more staff and more administrative support. If as educators, both in the library and the classroom, we are going to argue the relevance of free voluntary reading, or pleasure reading as an activity to be encouraged and supported, one thing we can do is look to and use effectively the research evidence which supports our, often, heart-felt belief that reading for pleasure matters.

\section{The relationship between pleasure reading and student achievement}

In making a case for the existence of a strong relationship between pleasure reading and student achievement we need look no further than a number of important, recent research studies from different areas of the world. This research evidence is powerful and compelling, I have explored its relevance in the past (La Marca, 2004), but it is worth revisiting. 
The relevant research studies include the Australian School Library Association's (ASLA, 2003) report Impact of School Libraries on Student Achievement: a Review of the Research, as well as two American reports - The American National Assessment of Education Progress report titled Trends in Academic Progress: Three Decades of Student Performance (Campbell, Hombo \& Mazzeo, 2000), which investigated the relationship between free voluntary reading and text scores in reading, and the report Independent Reading and School Achievement (Cullinan, 2000), which found strong links between positive attitudes towards reading and the amount of free voluntary reading that students undertake (Cullinan, 2000, p. 1). Cullinan also referred to a number of other research reports that found similar correlations, further strengthening her argument.

These research findings are replicated in the work of other commentators, most notably Krashen (2004). In reviewing a body of research he was able to claim that how much children read is related to how well they read (p. 4), and also Haycock, who, in a study of Canadian libraries noted that research supporting this relationship has been available for more than fifty years. Haycock claims that the relationship between achievement and voluntary reading crosses all the usual barriers to educational equity such as socio-economic background (Haycock, 2003, p. 17 \& 26).

Complementary findings appear in research undertaken across countries and cultures. For instance, Machet, describing the South African experience, found 'that a free voluntary reading program can improve children's grammar, reading and comprehension more than time spent on conventional language lessons' (Machet, 2000, p. 1). Perhaps the most comprehensive evidence comes from the OECD Program for International Student Assessment (PISA) study, reported in The Reading for Change document (2000), which investigated the reading habits of 260,000 fifteen-year-olds across thirty-two countries. The Executive Summary reported that: 'Students who read well tend to be active readers. They gain in terms of both motivation and experience from reading regularly outside the context of school work' (OECD, 2000, p. 12).

As teacher-librarians we must embrace research findings such as these and use them as support evidence when we plan programs, create policy documents that explain the relevance of our services and programs and when we assist in the development of curriculum planning, production and implementation.

Despite all the valuable and useful evidence that allows us to make a case by playing the bean counter's game, perhaps it is the factors that began this discussion that are ultimately most important though, unfortunately, perhaps the most difficult to assess. Saxby (1997) reminded us of the important links between reading and culture and Jennings recognises that it is pleasure that is at the centre of the reading experience. Jennings says: '..a problem with attainment testing is the narrow view as to what are the essential elements when a child learns to read. The most important things in life cannot be easily quantified. Love, courage, honesty, enjoyment and attitude are not easily measured by tests....A child's attitude to reading and the degree to which they love books are the most reliable indicators of their future progress, but these are not measured. The pressure that is placed on children to perform well on national benchmarks can destroy the very element which will lead to success - pleasure in the task' (Jennings in La Marca \& Macintyre, 2006, p. 12).

\section{The centrality of engagement to pleasure}

Pleasure reading, then, has value for a variety of reasons. Whether we encourage reading for pleasure for reasons of enjoyment and personal growth or in an attempt to lift achievement scores how we increase levels of pleasure reading remains a challenge. 
In attempting to describe the nature of the pleasure that we feel when we read we must acknowledge the reader's need to be engaged in the process of reading. This engagement goes hand in hand with pleasure. One description of the reading transaction is Csikszentmihalyi's idea of 'flow', that is, concentration and deep engagement - what he calls 'a deep sense of enjoyment' (1992, p. 4). His description of 'flow' evokes the reading experience that we want for young people. It includes the following:

- The mental manipulation of concepts

- The positioning of thinking as pleasurable

- The identification of the importance of patterns, likenesses, connectedness

- The facilitation of concentration and involvement

- The pursuit of an activity so pleasurable that it is undertaken for its own sake (Csikszentmihalyi, 1992, p.126)

In line with these views $\mathrm{Au}$ found that 'engagement is at the very heart of what it means to be a reader' (in Guthrie \& Alvermann, 1999, p. xi), and Guthrie found that engaged reading is 'a merger of motivation and thoughtfulness'(Guthrie, 2000). Engaged readers explore what they read in an attempt to learn about themselves and the world around them. They are motivated to learn, to discover and understand their motivation is intrinsic. Guthrie (2000) describes a student-centred learning process, one that is built upon a critical interaction with a text. This interaction relies on engaging students with books that they want to read, and positioning reading as an experience that they will choose to continue in their own time and into their adult lives. Creating an environment, a culture, which fosters this, is a crucial school practice. Such practices manifest themselves as curriculum, classroom and library reading experiences that are designed to encourage students' enjoyment of, and pleasure in, reading in the belief that pleasure underpins engaged reading. Good teachers and teacher-librarians are an important component in creating these contexts for engagement.

This approach necessitates that teachers and teacher-librarians work in partnership to position reading across the school as an inherently pleasurable activity, one that is linked strongly to academic success not through tests and assessment but by providing an environment that encourages a culture of thoughtful and analytical reading fostering the enjoyment and challenge which rich texts offer. From their first days at school it is important that students are not just taught to decode symbols but are engaged in reading as a meaningful part of their lives.

The OECD report 'Reading for Change' (2000) found that 'The results show unequivocally, that improvement in reading literacy performance relies not just on improving student cognitive skills but also on increasing their engagement in reading' (OECD, 2000, p. 22). The establishment and improvement of engagement, the report goes on to argue, 'cannot be seen as an add-on to curriculum reforms, but must be seen as central' (OECD, 2000, p. 22). Contingent on this is 'access to interesting and meaningful reading materials' (OECD, 2002, p. 121). Guthrie and Alvermann explore at length what we need to do to create engaged readers. They have said 'creating classroom communities, providing challenging tasks, and allowing students to make choices characterise effective practices that connect to students' interests and motivations. Connecting to students' interests and values ultimately can produce motivated, engaged readers'(Guthrie \& Alvermann,1999, p. 23).

To enable readers to become engaged in their reading schools need to begin by recognising and valuing the out-of-school reading that students do and building on (though not appropriating) those reading skills and preferences. In a community of readers the 
interests and views of all readers are valued even if the preferences of some may not be mainstream or literary in an academic sense. This goes hand in hand with the importance of providing access to a range of diverse texts that students want to read, texts that challenge them and also texts that make them feel comfortable and part of a community of readers. As Chambers says 'People do not become committed readers on a diet of prescribed texts only, however well chosen they might be...We cheerfully become willing readers when following our own instincts and tastes' (1991, p.4). These instincts and tastes may be far ranging and experimental in type and form of text but they must all be rich and engaging. Margaret Meek reminds us, 'makes skilful, powerful readers who come to understand not only the meaning but also the force of texts' (Meek, 1989, p. 40).

A 1999 study into the reading habits of young people in Britain showed that 'Children are reading more books now than their parents did in the seventies' (Hall \& Coles, 1999). This study compared the habits of 8000 young people with a similar, well-known study by Whitehead, undertaken in 1971. Coles and Hall found that the generation they studied was reading more, though not from the 'classics' but from newspapers and modern popular fiction, a constantly changing, varied diet of material. The work of Krashen (2004) and others supports this view that young people continue to find pleasure in reading as an activity.

Recent reports have suggested that students are not reading, particularly literary texts as often as they once did. Reports such as the National Endowment for the Arts Reading at Risk research said: 'The trends among younger adults warrant special concern, suggesting that - unless some effective solution is found - literary culture and literacy in general, will continue to worsen. Indeed, at the current rate of loss, literary reading as a leisure activity will virtually disappear in half a century' (2004, p. xiii).

In response, commentators such as Krashen have taken a slightly different approach, celebrating the positive and offering simple, sensible solutions to these gloom and doom prophecies. In doing so, Krashen again champions the importance of access, choice and variety. He said, '...we have to get the good news out: Self-selected voluntary reading is beneficial and pleasant, and is highly effective. Also, it is not difficult to get children involved in reading. For a fraction of what we are investing in testing, and in programs that clearly do not work, we could easily ensure that all children have access to quality reading. When this happens, literacy crises, real or imaginary, will be a thing of the past' (Krashen, 2008, p. 21).

Krashen sees access, choice and variety as central components for supporting and building young readers. Instrumental in this process is the teacher-librarian or the classroom teacher, what Chambers calls the enabling adult (Chambers, 1991).

\section{The teacher librarian as an enabling adult}

As interested professionals, we all work hard at bringing students and books together. This is what Chambers $(1991,1993)$ saw as the work of the enabling adult - finding the right book for the child in line with their interests and needs, talking to them about their reading and enabling them to begin this cycle again. This cycle of selecting, reading, interacting and selecting again is what Chambers termed the 'reading circle' (Chambers, 1991). The role of the enabling adult is to foster pleasure and engagement in this process. Baker, Dreher and Guthrie (2000) said that 'What is clear from the research on teacher effectiveness is that educators passion for the subject matter is contagious ...In effect, teaches should share their love of reading by demonstrating its importance and beauty to children on a daily basis' ( $p$. 304).

A recent British report by the National Literacy Trust - Reading for pleasure: $A$ research overview (Clark, C. \& Rumbold, K., 2006) stressed the importance of intrinsic 
motivation to the levels of engagement and therefore levels of pleasure our students found in the reading experience. This research overview quoted a number of commentators in the field. In particular they noted Wigifield and Guthrie's 1997 report which found that there were several factors that related to intrinsic motivation that predict reading breadth and comprehension. These were: 'importance, curiosity, involvement and challenge' (Clark \& Rumbold, 2006, p. 19). That is the 'importance', or relevance of the text to their lives, a factor which supports the efforts of teacher-librarians to create collections that offer a breadth and depth of reading options. 'Curiosity' the need to find, and supply, reading experiences that will interest and tantalise, our students. Clark and Rumbold's other two factors 'Involvement' and 'challenge' - also support the need for a comprehensive library collection. This terminology suggests a student- centred approach where interests and needs are meet by the reading experience. Thomson says: (we need) 'to be able to help individuals find books that are likely to be most meaningful to them...whatever their reading experience' (Thomson, 1997, p. 33).

These views support the wide ranging importance many commentators (Krashen, 2003; Bunbury, 1995; Strickland, Ganske and Monroe, 2002; La Marca \& Macintyre, 2006) place on the need to provide choice, access and variety. To facilitate this teachers and teacherlibrarians need to have a variety of texts to draw on, close knowledge of the individual student's abilities and tastes, and strategies that support students as they become independent in selecting for themselves.

To work with young people as enabling adults we need a variety of skills. Nodelman \& Reimer said 'Since a main pleasure of literature - and a main way of learning more about how to enjoy it - is the dialogues it engenders, good teachers will want to encourage dialogue, both among children and between children and themselves'(2003, p. 46). They suggest that one of the most important skills that we must learn how to do well is the sharing of pleasure in reading based around the most basic of human interactions - talk. The role of literature has always been to provoke and invite questions not to provide answers and one of the most important roles for the teacher-librarian is not to tell the students how to respond to or interpret what they read but to help them articulate their own responses. This supportive interaction helps build a sense of community; it helps to establish relationships around shared reading experiences and ultimately leads to pleasure in reading.

A rich and diverse library collection, a welcoming library environment and a sense of a community of readers are structures that support choice and talk. Without them, the possibility of choice is jeopardised particularly for those students who have little external access to reading materials. As a collection builder, a provider of equitable access and a knowledgeable, accessible mediator the teacher-librarian has a powerful role to play in facilitating choice and offering variety. Haycock (2003) has found that 'teacher-librarians typically place the right book in the right hands at the right time and encourage a lifelong love of reading (Barlup, 1991). The role of the teacher-librarian in connecting young people with books that interest them, has been underestimated' (p. 27).

\section{In practice}

\section{Photo Story}

Nodelman (1996) stresses the importance of sharing with students what experienced readers do when they explore and respond to a text. The importance of talk in this process has already been highlighted. A number of commentators have created ways of assisting students 
to explore the way texts work through talk. One of the most useful is Chambers's 'three sharings' (1993). In this model he encourages readers to share their enthusiasms - what did you like/dislike?, their puzzles - what did it mean when...? Did you understand when...?, and patterns or connections - world-to-text, text-to-text, self-to-text.(Chambers, 1993).

Recently I worked with a group of students who had read a range of excellent Australian teenage fiction that had been shortlisted for one of our national awards. We had the luxury of time to talk and analyse what we had read, discussing our likes and dislikes, our puzzles and connections. The exercise attempted to replicate the judging process that is carried out by adults, but in this case, the students were the 'judges'. They responded with wonderful discussion about the merits and strengths of the various texts, using Chambers's three sharings approach facilitated discussion technique.

As a culmination to this wonderful talk students were invited to create a response to one of the texts utilising the Microsoft program Photo Story. Photo Story is freeware and allows the user to collect together, sequentially, a series of images, incorporate audio, and insert captions. The students were asked to encapsulate the book in images and music. They were to represent how they saw the book and what it meant to them. The results were extraordinary and led to more talk and discussion as students viewed each others short photo and audio montages. They further developed their understanding by talking through the various images and interpretations.

This exercise was engaging and stimulating. It offered choice, variety and talk in a user-friendly form of response that was open to interpretation and manipulation. It created, for a short time a community of readers that found pleasure in not only reading but also in responding to text.

\section{Text centred thematic unit}

Chambers's 'three sharings' approach encourages students to see patterns and connections - world-to-text; text-to-text; self-to-text (Chambers, 1993). It can be used with one text or with many. Units can be created that link a number of different text types under a common theme. Students can then, with the assistance of some leading questions, be encouraged to make connections and see patterns between and beyond the texts to their own world and the wider world. Whilst these theme-based studies are common in the primary or elementary area they are not so readily attempted in the senior or secondary years of schooling in Australia. The strength of this approach lies in the scope it offers for embracing a variety of text types. The following texts might be grouped together for a unit entitled 'In a modern world' which could be underpinned by a series of questions based around the notion of how we live our lives and interact with each other.

\section{In a modern world}

Possible texts:

- Frankfurt, H. G. (2005) On bullshit, Princeton University Press.

- Dimmeys and David Jones Advertising catalogues.

- Hamilton, C. \& Denniss, R. (2005) Affluenza: When too much is never enough, Allen \& Unwin. 
- Hopper, E. Nighthawks (artwork)

- Hyland, M. J. (2004) How the light gets in, Penguin. (novel)

- Munch, E. The scream (art work)

- Riddle, T. (2000) The singing hat, Penguin.(picture book)

- Simpsons (television series)

- Spurlock, M. (2005) Don't eat this book, Penguin.

- Super size me (2004) Directed by Morgan Spurlock (documentary film)

- Tan, S. (2000) The lost thing, Lothian. (picture book)

- Tashian, J. (2004) The Gospel According to Larry, Puffin. (novel)

- Thompson, C. \& Lissiat, A. (2005) The short and incredibly happy life of Riley, Lothian.(picture book)

- Warhol, A. Campbell's soup can (artwork)

- Westerfeld, S. (2005) So yesterday, Penguin (novel)

- Who weekly (magazine)

- Youth Society pages from The age (major daily newspaper)

Whilst students explore connections and puzzles through interaction and talk based on rich texts that offer variety and depth, they are encouraged to think and question.

\section{Conclusion}

Our libraries are vibrant, interesting places that offer a wealth of opportunity to our students. The task of assisting students to become engaged readers who find pleasure in reading as an activity is not a chore but a gift. It allows us to explore, with them, the rich and thoughtful offerings, the variety of mediums, views and approaches that make up our world. Being an enabling adult is both rewarding and meaningful and allows us to assist in creating the next generation of creative, thoughtful, analytical thinkers.

\section{References}

Baker, L., Dreher, M. J. \& Guthrie, J. T. (2000) Engaging young readers: Promoting achievement and motivation. New York: The Guilford Press.

Baumann, J.F. \& Duffy, A.M. (1997). Engaged reading for pleasure and learning: A report from the National Reading Research Center. Eric Document 413579.

Bunbury, R. (1995) Children's choices: Reading at home or at school. Geelong: Deakin University Press.

Campbell, J. R., Hombo, C. M., \& Mazzeo, J. (2000). 1999 trends in academic progress: Three decades of student performance. (online report) NAEP (National Assessment of Education Progress) Washington DC: Department of Education. Available at: www.nifl.gov/nifl/facts/reading-facts.html 
Chambers, A. (1991). The reading environment. NSW: PETA, Thimble Press.

Chambers, A. (1993). Tell me: Children reading and talk. Stroud: The Thimble Press.

Clark, C. \& Rumbold, K. (2006). Reading for pleasure: A research overview. National Literacy Trust. Available at: www.literacytrust.org.uk/research/Reading\%20for\%20pleasure.pdf

Csikszentmihalyi, M. (1992) Creativity: Flow and the psychology of discovery and invention. New York: HarperCollins.

Cullinan, B. E. (2000). Independent reading and school achievement. Commissioned as part of a national study Assessment of the Role of School and Public Libraries in Support of Educational Reform. (Originally prepared for the U.S . Department of Education). New York: American Library Association. Available at:

http://www.ala.org/PrinterTemplate.cfm?Section=Volume 3 (2000)...HTMLDisplay.cfm\&ContentID= $\underline{2523}$

Guthrie, J. T. (2000). 'Contexts for engagement and motivation on reading' in Pearson, D (editor) (2000) Handbook of reading research: volume III, New York Longman.

Guthrie, J. T. \& Alvermann, D. E. (editors) (1999). Engaged reading: Processes, practices and policy implications. New York: Teachers College Press.

Hall, C. \& Coles, M. (1999) Children's reading choices. London: Routledge.

Haycock, K. (2003) The crisis of Canada's school libraries: The case for reform and re-investment. Toronto: Association of Canadian Publishers.

Krashen, S. D. (2004). The power of reading: Insights from the research. (Revised Edition) Englewood, CO: Libraries Unlimited.

Krashen, S. D. (2008). 'Ending all literacy crises' in Language, May, pp. 20-21.

La Marca, S. (2004). 'Free voluntary reading and the role of the teacher librarian' in From Aesop to e-book: The story goes on...IASL Reports, 2004: Selected Papers from the 33rd annual conference of the International Association of School Librarianship, and the 8th International Forum on Research in School Librarianship. Dublin, Republic of Ireland, 17-20 June 2004. Edited by Penny Moore, Eleanor Howe, Ray Lonsdale, Rachel McCahon and Diljit Singh. IASL.

La Marca, S. \& Macintyre, P. (2006). Knowing readers: Unlocking the pleasures of reading. Carlton, Victoria: School Library Association of Victoria.

Machet, D. M. (2000) 'Reading for pleasure' in Sunday Times, South Africa, $19^{\text {th }}$ June.

Meek, M. (1988). How texts teach what readers learn. South Woodchester, Gloc. : The Thimble Press.

National Endowment for the Arts (2004) Reading at risk: A survey of literary reading in America. National Endowment for the Arts. Available at: www.nea.gov/pub/ReadingAtRisk.pdf

Nodelman, P. \& Reimer, M. (2003). The pleasures of children's literature. (Third edition) Boston, MA: Pearson Education.

OECD (2000). Reading for change: Performance and engagement across countries. Results form PISA 2000. (Executive summary) PISA (Program for International Student Assessment). Available at: www.pisa.oecd.org/Docs/Download/ReadingExeSummary.pdf

Saxby, M. (1997) Books in the life of a child: Bridges to literature and learning. South Melbourne: Macmillan Educational. 
Strickland, D. S. , Ganske, K. \& Monroe, J. K. ( 2002) Supporting struggling readers and writers: Strategies for classroom intervention 3- 6. Portland, Maine: Stenhouse Publishers.

Wigfield, A. \& Guthrie, J. T. (1997) 'Relations of children's motivation for reading to the amount and breadth of their reading' in Journal of Educational Psychology, 89, pp. 420 - 432.

\section{Biographical Notes}

Dr Susan La Marca is a teacher-librarian at Ivanhoe Girls' Grammar School in Melbourne, Australia. She is also the editor of Synergy, the research journal of the School Library Association of Victoria and associate editor of the journal Viewpoint: on books for young adults and she works as a consultant in the areas of children's and young adult literature and libraries.

Susan has edited a number of texts in the field of teacher-librarianship including Back to Books: Creating a Focus on Fiction (1999), Books up Front: Investing in the Value of Reading (2001), Effective Learning Spaces: Inspirational Library Design (2003) and Rethink!: Ideas for inspiring School Library Design (2007). She is also the co-author with Dr Pam Macintyre of Knowing Readers: Unlocking the Pleasures of Reading (2006).

\section{Statement of Originality}

This statement certifies that the paper above is based upon original research undertaken by the author and that the paper was conceived and written by the author(s) alone and has not been published elsewhere. All information and ideas from others is referenced. 